\title{
Managing and Communicating Operational Workflow
}

\section{Designing and Implementing an Electronic Outpatient Whiteboard}

Bryan D. Steitz ${ }^{1}$; Stuart T. Weinberg ${ }^{1,2}$; Ioana Danciu'1, 3; Kim M. Unertl ${ }^{1}$

${ }^{1}$ Department of Biomedical Informatics, Vanderbilt University School of Medicine; ${ }^{2}$ Department of Pediatrics, Vanderbilt University School of Medicine; ${ }^{3}$ Department of Quality Safety and Risk Prevention, Vanderbilt University Medical Center

\section{Keywords}

Workflow, health information technology, decision making, ambulatory care

\section{Summary}

Background: Healthcare team members in emergency department contexts have used electronic whiteboard solutions to help manage operational workflow for many years. Ambulatory clinic settings have highly complex operational workflow, but are still limited in electronic assistance to communicate and coordinate work activities.

Objective: To describe and discuss the design, implementation, use, and ongoing evolution of a coordination and collaboration tool supporting ambulatory clinic operational workflow at Vanderbilt University Medical Center (VUMC).

Methods: The outpatient whiteboard tool was initially designed to support healthcare work related to an electronic chemotherapy order-entry application. After a highly successful initial implementation in an oncology context, a high demand emerged across the organization for the outpatient whiteboard implementation. Over the past 10 years, developers have followed an iterative usercentered design process to evolve the tool.

Results: The electronic outpatient whiteboard system supports 194 separate whiteboards and is accessed by over 2800 distinct users on a typical day. Clinics can configure their whiteboards to support unique workflow elements. Since initial release, features such as immunization clinical decision support have been integrated into the system, based on requests from end users.

Conclusions: The success of the electronic outpatient whiteboard demonstrates the usefulness of an operational workflow tool within the ambulatory clinic setting. Operational workflow tools can play a significant role in supporting coordination, collaboration, and teamwork in ambulatory healthcare settings.

\section{Correspondence to:}

Bryan D. Steitz

Department of Biomedical Informatics Vanderbilt University Medical Center 2525 West End Ave. Suite 1475

Nashville, TN, 37232

Email: bryan.steitz@vanderbilt.edu
Appl Clin Inform 2016; 7: 59-68

http://dx.doi.org/10.4338/ACl-2015-07-CR-0082

received: July 9, 2015

accepted: December 6, 2015

published: February 3, 2016

Citation: Steitz BD, Weinberg ST, Danciu I, Unertl KM. Managing and communicating operational workflow: Designing and implementing an electronic outpatient whiteboard. Appl Clin Inform 2016; 7: 59-68 http://dx.doi.org/10.4338/ACl-2015-07-CR-0082 


\section{Introduction}

Workflow in ambulatory clinic settings involves multiple facets of patient care managed by individuals holding different roles and having different perspectives on care [1]. Operational workflow includes: tracking patient movement through a clinic [2], understanding the status of resources and physical space [3], representing resource data in a useful format [4] and coordinating work among many resources [5]. Tools that assist healthcare team members with developing shared situation awareness about operational workflow are well documented in the emergency department environment [6]. Locally developed and vendor-developed systems provide electronic whiteboard features intended to replace physical non-electronic whiteboards [6] for perioperative [7, 8], inpatient [9], and emergency department [6,10-12] contexts. Electronic whiteboard tools for use in emergency departments have included tracking and information flow features available only in computer applications [10-12].

Electronic tools for managing operational workflow are less commonly discussed in the ambulatory clinic context, despite high levels of work complexity and the need to coordinate work across many team members [13]. Management of operational workflow in the ambulatory clinic environment has taken many different forms. Traditional approaches such as use of different color flags above exam room doors help healthcare team members communicate with each other about room status and coordinate patient care and room management activities [14]. Our research has also previously documented use of electronic communication approaches to support ambulatory operational workflow, such as a nurse paging a physician when patient intake activities are completed [13]. Despite the lack of documentation in the literature regarding computerized whiteboards in ambulatory settings, the need for this type of computerized tool seems clear.

This case report discusses the design, implementation, use, and ongoing evolution of a coordination and collaboration tool supporting ambulatory operational workflow at Vanderbilt University Medical Center (VUMC).

\section{Methods}

The tool, known as the electronic outpatient whiteboard (OPWB), is currently used in over 180 VUMC ambulatory clinics throughout middle Tennessee and southern Kentucky. Use contexts for the tool range from small community practices to high throughput academic medical center clinics, including general practice environments, specialty clinics, and procedure-oriented oncology infusion centers.

\subsection{Technical Design}

The OPWB application resides on two server clusters tasked with supporting VUMC's electronic health record, StarPanel ( $\triangleright$ Figure 1). A MySQL-based infrastructure [15] operates the application, which is supported by numerous services ( Table 1). All of the demographic and appointment information that appears in the OPWB comes from the electronic scheduling system in near real-time. When a scheduling event occurs (e.g., scheduling or re-scheduling of an appointment, cancellation of an appointment, or arrival of a patient for an appointment) an HL7 [16] message is generated by the scheduling system and sent to the General Interface Engine (GIE). A concurrent, perpetually running, script listens for these messages from the GIE and places them in a temporary MySQL table, which is cleared at the end of each day. A second script accesses the temporary table in 20-second intervals to identify the new messages and parses them into the production tables used by the whiteboard application. Processing of information more than three days out is deferred until evening to prevent overloading the system during high activity periods, allowing the system to focus on real-time messages [17]. Data from the application, including room movement data and workflow status flag changes, are sent to an Enterprise Data Warehouse daily for later analysis and reporting. 


\subsection{Design and Implementation: Oncology}

The whiteboard concept emerged from the collaboration between frontline healthcare staff and a biomedical informatics researcher and physician (STW), during a wider effort to design and implement an outpatient chemotherapy computerized order entry system (CPOE). As a result, the initial version of the electronic OPWB focused on oncology clinics and outpatient chemotherapy infusion centers. Healthcare team members identified managing operational workflow as a potential challenge with CPOE. An iterative design process led by a physician trained in biomedical informatics (STW) was followed for tool development. Weekly meetings to discuss the CPOE design and implementation effort served as an opportunity to discuss and provide feedback about the whiteboard design. Initial design of the OPWB was similar to design of an existing emergency department whiteboard at VUMC [18]. Feedback from healthcare team members in oncology environments were used to adapt design features to the specific needs of ambulatory oncology care. Production HL7 messages began populating the outpatient whiteboard in December 2004, and the system was implemented in pediatric and oncology clinics in mid-2005.

\subsection{Ongoing Implementation Across the Organization}

After the initial successful implementation in oncology, a high demand for this type of workflow management tool emerged across the organization. Because the design process took a deliberate approach to scalability, the process of moving from a single clinical environment to a variety of ambulatory settings was simplified. As clinics requested whiteboard access, implementation specialists from the health information technology operations group along with the clinical informatics leader assisted clinics with initial set up of the tool. A key aspect of the scalable design approach is the ability to customize the appearance and features of the OPWB from clinic to clinic. Additional functionality has been added as a result, including workflow flags to accommodate new workflows, influenza decision support, and support for a patient pager system in some clinics. As additional functionality was added, more formal usability evaluation meetings consisting of users, developers, and senior organizational leadership ensued [19]. These meetings allowed for design-related discussions regarding new OPWB features and necessary changes to existing features. All proposed changes were evaluated and prioritized during the meeting, and subsequently implemented by the developers.

\section{Results}

Data from nearly 9,000 scheduled patient visits per weekday are tracked in 194 unique whiteboards based on daily averages from May 2015. The outpatient whiteboard facilitated, on average, over 45,000 transition events in the same month. In the past six years, the number of daily outpatient whiteboard users has grown greatly ( $>$ Figure 2). A user is defined as any individual who inputs data into the whiteboard. The outpatient whiteboard currently has over 14803 total users, with over 2800 unique users accessing the system on an average weekday.

\subsection{Electronic Outpatient Whiteboard Design}

The design of the OPWB uses a table-based layout ( Figure 3). Each of the columns represents specific categories relating to a visit such as current room, patient name, and workflow flags. Each row represents a particular appointment. Within each row, individual cell colors are dynamically modified based on predefined parameters such as the state of a workflow flag or order progress. Blue text in a cell indicates fields that can be clicked to obtain additional information, while black text indicates fields that do not have additional information beyond displayed data. If a user clicks on the patient name, the application takes the user directly to the patient's electronic medical record. Similarly, when hovering over cells, a brief "snapshot" of additional information is provided when available. 
The top bar of the OPWB provides the ability to modify view options. A user can change to different clinics whiteboards, filter patients, or change dates. Buttons to perform basic administrative tasks are also present.

\subsection{Workflow Overview}

Use of the whiteboard in practice varies, due to multiple factors. The general OPWB structure serves as a communication bridge across healthcare team members and provides basic support for common workflow components including: communication, patient movement tracking among different physical spaces, process management, workflow flags that provide visual cues of task status, and clinical decision support through automatic whiteboard flags that reflect patient status. The adaptable design of the tool accommodates workflow details unique to specific clinical contexts, such as tracking chemotherapy infusion status from order to administration.

Clinics with in-house whiteboard expertise can easily modify whiteboard features such as room names. For example, some clinics add the name of the physician assigned to an exam room on a specific day to the formal room name in the whiteboard. Some healthcare teams found this type of "on the fly" modification helpful in managing operational workflow. Clinics without in-house whiteboard expertise could request modifications to features of their clinic whiteboard by the development team. While the appearance and features of the whiteboard can be customized from clinic to clinic, one underlying platform supports all OPWB activity. This simplifies analysis of whiteboard data across the institution and provides a core set of common capabilities that can be easily maintained and tailored from a central resource.

\subsection{Ongoing Evolution}

The electronic outpatient whiteboard has evolved continuously over the last ten years. Changes have ranged from minor modifications to significant new capabilities such as CPOE integration. Driving forces for change have included: clinics moving to new physical spaces, feature requests from specific clinics, responses to emerging priorities across the entire clinical enterprise, and implementation of new health information technology systems.

The design of physical space has played a significant role in the demand for OPWB capabilities. Although the intent of the original design focused on oncology clinics, shortly after the initial oncology implementation, VUMC opened a new pediatric ambulatory clinic office tower. The workspace design located physician workrooms in a back hallway, physically separated from exam rooms and nursing stations. The layout impeded communication across the healthcare team and created challenges in awareness about exam room status. On the second day after the new office tower opened, clinical staff contacted the outpatient whiteboard team seeking a solution, resulting in the addition of 21 new whiteboards over a two-year period.

One of the greatest contributions of the electronic OPWB has involved reducing missed opportunities. An example of this is an influenza vaccination status column on many of the primary care and specialty clinic whiteboards. The whiteboard provides underlying analysis of the influenza vaccination status of patients and provides simple clinical decision support in the form of an influenza vaccination status flag. This decision support intervention simplified the complex influenza vaccination algorithm in the pediatric population and proved especially helpful in a teaching institution, where healthcare team members have varying degrees of knowledge about interpretation of immunization algorithms. In addition, individual immunization needs are placed in a location where everyone on the healthcare team can see the information, rather than burying it within each specific patient's record. As such, users responded to over $90 \%$ of the immunization alerts, greatly increasing the number of vaccines given from previous years [20].

Other features of the whiteboard also play a role in communication across healthcare teams and in improving patient interaction with the healthcare system. For example, the VUMC interpreter services team, a centrally located service not linked to a specific clinic, has a dedicated whiteboard. When clinic staff requests an interpreter, interpreter services marks on their whiteboard when an interpreter has been dispatched. This information propagates through the system, providing feedback to the requesting clinic that an interpreter is on the way. This type of cross-institutional communi- 
cation is important for physically distributed services and supports situation awareness across the institution.

\subsection{Challenges Facing the Outpatient Whiteboard}

As the organization moves in new directions with new priorities, a disconnect has emerged between organizational redesign efforts and OPWB integration. The OPWB was written in PHP [21] for integration with a proprietary electronic health record system; future migration to a commercial electronic health record system could prove challenging. Similarly, staffing requirements to handle such a migration must be addressed.

\section{Discussion}

The design and implementation of the electronic outpatient whiteboard at VUMC demonstrates the importance of flexibility and customization based on contextual factors. The flexible design of the tool promoted rapid uptake in diverse environments spread out across a large clinical enterprise, including physically distributed clinical environments. The widespread growth of the outpatient whiteboard was unexpected in many ways. The tool was originally designed to fit the specific needs in the oncology infusion setting. Nevertheless, organizational buy-in was a response to the perceived utility of the tool. Such quick uptake can be attributed to the whiteboard's agile infrastructure, allowing for ideas to be quickly implemented when conceived by a clinic. When deemed beneficial, these ideas can also be implemented in additional clinics. This distributed brainstorming process leverages the experience of the entire institution to further innovate the outpatient whiteboard and to support operational workflow.

Clinical reliance on the outpatient whiteboard has introduced a valuable but relatively underused resource for clinic managers and workflow researchers. However, ease of system modification within clinics has increased the difficulty of analyzing electronic whiteboard data over time and across clinical environments. This has limited the utility of electronic whiteboard data for organization-level analysis and decision-making. Data from the electronic whiteboard could be valuable in helping to understand bottlenecks in patient flow, staffing requirements, and room utilization. The variety of implementation strategies across the clinics, however, has created difficulty in analyzing the information on a clinic-by-clinic basis, much less advancing this analysis to a higher organizational level.

\subsection{Lessons Learned}

Demand for OPWB features led to many requests for additional features and integration with specific clinic workflow processes. A larger integration team would have allowed for additional resources to provide user training to develop best practices. Similarly, given staffing limitations, thorough documentation was not created. Both user training and the creation of documentation may have streamlined implementation, ongoing support, and future development of the application.

\subsection{Future Work}

The OPWB has been well integrated into existing clinical workflow, but few studies have been conducted to evaluate the impacts. Next steps are to further evaluate the impact of the OPWB on clinician workflow surrounding improved situational awareness. Similarly, the OPWB has provided an aggregate of workflow and operational data, which permits quantitative workflow analysis.

\section{Conclusion}

Electronic whiteboards in ambulatory care settings allow for more efficient solutions to the traditional, non-electronic, workflow management approaches. The electronic outpatient whiteboard at 
VUMC has been met by extraordinary user adoption and acceptance. As a result of an iterative usercentered design process and substantial user feedback, the electronic whiteboard has seamlessly integrated with existing workflow patterns.

\section{Clinical Relevance Statement}

The electronic outpatient whiteboard and other operational workflow coordination tools offer opportunities to enhance a clinic's coordination and efficiency. Healthcare team members must communicate effectively to deliver optimal and efficient care. Operational workflow tools, particularly within the ambulatory setting, can streamline collaboration and support teamwork.

\section{Conflicts of Interest}

The authors have no conflicts of interest to report.

\section{Human Subjects Protection}

The Vanderbilt University Institutional Review Board (IRB) determined this project to be exempt from further review as this activity did not involve research on human subjects. 


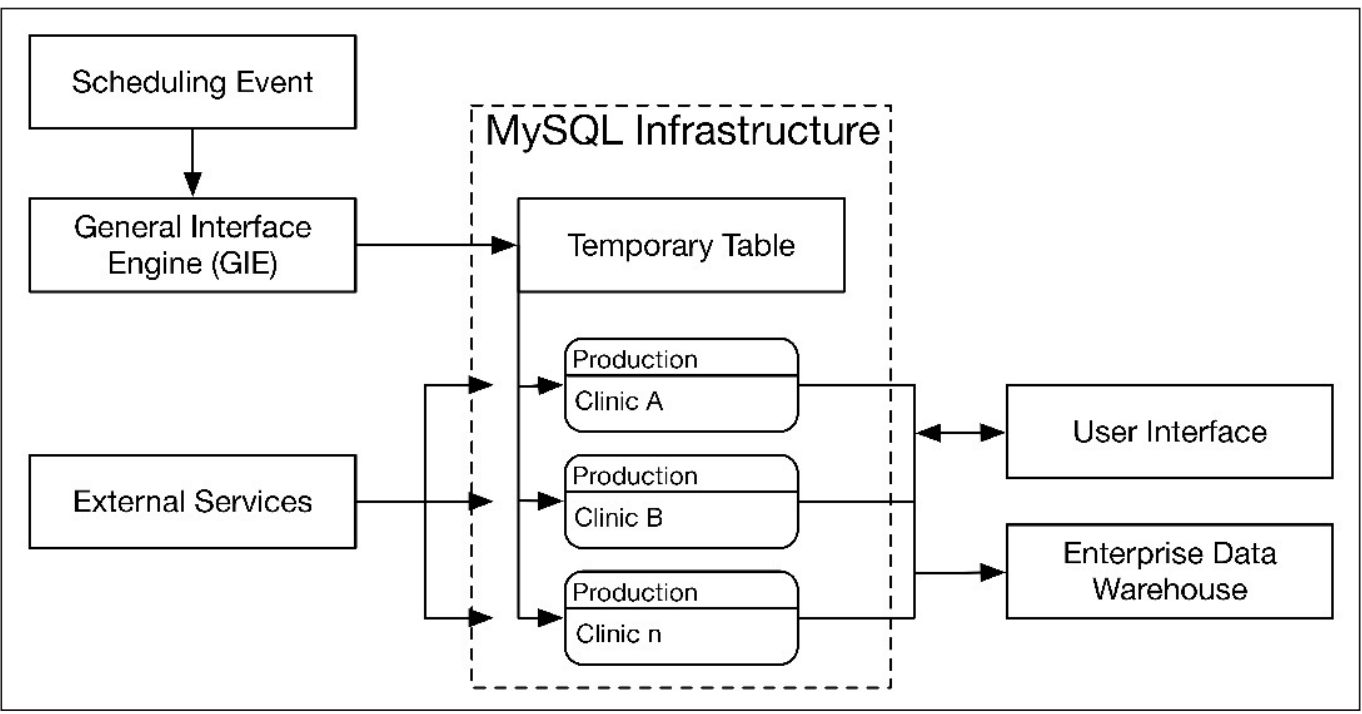

Fig. 1 Technical Design of the OPWB

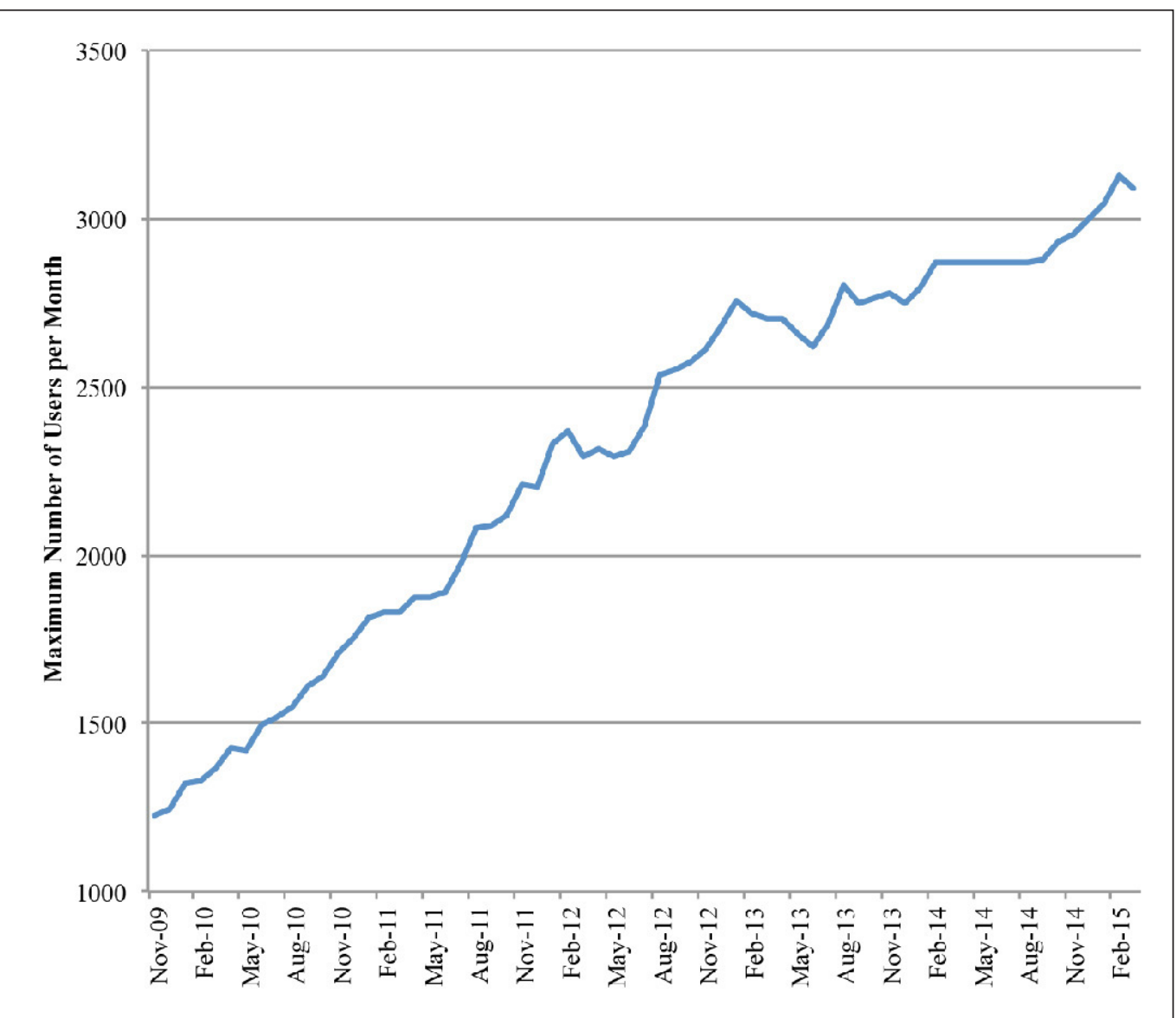

Fig. 2 Maximum Number of Daily OPWB Users per Month 


\begin{tabular}{|c|c|c|c|c|c|c|c|c|c|c|c|c|c|c|c|c|c|c|c|}
\hline 표 & 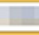 & 11 & 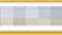 & 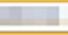 & & $\hat{\imath}$ & & & Scheduled $\hat{v}$ in & All De & ay & 0 on & & « & 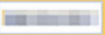 & " & & Today: & 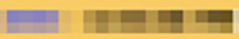 \\
\hline User & 国 & $=$ & . & & & $\mathrm{Scr}$ & iedu & le(s) & Rooms & & Prefs & & & kup & & Adm & & Help & En \\
\hline & $\square$ r & Hide L & Inchec & & Ineng & $\square$ & $=$ & 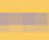 & O & a & $\square=$ & $=$ & 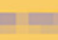 & In & En & 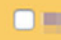 & 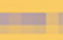 & $\square$ & 표 \\
\hline Q I & $+=$ & $1=$ & Q & 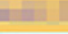 & Combi & & tal $A$ & Appts & $: 68$ (FLS: 0) [AM/PM] & & & & & & & & & & \\
\hline $\mathrm{TSB}$ & Tdy & Cal & $\mathbf{R m}$ & Appt & Status & In Rm & $\mathbf{L}$ & Ints & Pationt Name (MRN) & Pago & Actions & Voom & Ago & $\mathbf{s}$ & Typo & Fluvs & TWIS & Providor & Appt Notos \\
\hline$\square$ & 1 & C & (D1) & $08: 20$ & arr 08:29 & $36 \mathrm{~min}$ & $E$ & -- & in & (76) & sp wb & 2 & E & II & Return P & -- & $n / m$ & in & 페 \\
\hline$\square$ & 1 & C & (A1) & $08: 40$ & arr 08:38 & $52 \mathrm{~min}$ & $E$ & -- & $\square$ & (393) & sp wb & 3 & = & 표 & Acute $V_{i}$ & -- & H & DF & 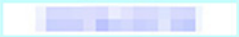 \\
\hline$\square$ & 1 & C & (D2) & $08: 40$ & arr 08:50 & $34 \mathrm{~min}$ & $E$ & -- & 맘 & (88) & sp wb & 0 & 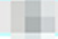 & 묘 & New Pati & -- & $n / m$ & Ela & D \\
\hline$\square$ & 1 & C & (C1) & $09: 00$ & arr 08:58 & $59 \mathrm{~min}$ & $E$ & -- & 미 & (111) & sp wb & 0 & 口 & 푸 & Return $\mathrm{P}$ & -- & $\mathrm{n} / \mathrm{m}$ & 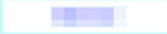 & 릴 \\
\hline$\square$ & 1 & C & (B4) & $09: 00$ & arr 08:59 & $51 \mathrm{~min}$ & $E$ & -- & 만 & (117) & sp wb & 2 & 뭄 & In & Return P & -- & D & ining & \\
\hline$\square$ & 1 & C & (A4) & $09: 00$ & arr 08:28 & $60 \mathrm{~min}$ & $E$ & -- & $=$ & (391) & sp wb & 2 & 口 & $=$ & Annual $\mathrm{P}$ & -- & D & 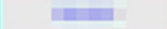 & mainning \\
\hline$\square$ & 1 & C & (A2) & $09: 00$ & arr 08:53 & $65 \mathrm{~min}$ & $E$ & -- & 른 & (395) & sp wb & $\cdots$ & 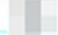 & 볼 & Acute $V_{i}$ & -- & H & ining & 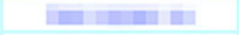 \\
\hline$\square$ & 1 & C & (D1) & $09: 00$ & arr 09:05 & $72 \mathrm{~min}$ & $E$ & -- & Eivi & (120) & sp wb & 0 & E & III & Annual $\mathrm{P}$ & -- & $n / m$ & 2 & E \\
\hline$\square$ & 1 & C & (C2) & $09: 20$ & arr 09:29 & $40 \mathrm{~min}$ & $E$ & -- & IIII & $(401)$ & sp wb & 0 & $=$ & 플 & Return $P$ & -- & P & Iis & 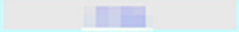 \\
\hline$\square$ & 0 & C & $-\cdot$ & $09: 20$ & CANCEL & -. & $E$ & -- & 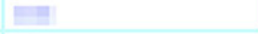 & $\cdots$ & sp wb & 1 & 밈 & = & Acute $V_{i}$ & -- & D & 国 & 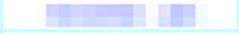 \\
\hline$\square$ & 1 & C & - & $09: 20$ & & -. & $E$ & - & 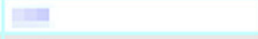 & - & sp wb & -- & In & = & Annual P & -- & $\mathrm{H}$ & 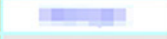 & 분 \\
\hline$\square$ & 1 & C & (D2) & $09: 40$ & arr 09:49 & $53 \mathrm{~min}$ & E & -- & $=$ & (120) & sp wb & 1 & = & $=$ & New Pati & -- & H & 달 & 플 \\
\hline$\square$ & 1 & C & -- & $09: 40$ & & -. & $E$ & -- & $E$ & - & sp wb & $\cdots$ & $=$ & = & Acute $V_{i}$ & -- & D & inis & in man \\
\hline$\square$ & 1 & C & (C3) & $09: 40$ & arr 09:24 & $69 \mathrm{~min}$ & E & -- & $E$ & (99) & sp wb & $1 / 1$ & 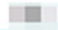 & E & Return $\mathrm{P}$ & -- & H & ini & 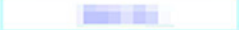 \\
\hline$\square$ & 1 & C & (A5) & $09: 40$ & arr 09:22 & $32 \mathrm{~min}$ & $E$ & -- & EIII & (398) & sp wb & 2 & E & 표 & Return P & -- & D & 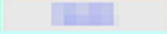 & 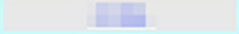 \\
\hline$\square$ & 1 & C & (A4) & $10: 00$ & arr 09:58 & $62 \mathrm{~min}$ & $E$ & -- & E & (68) & sp wb & 0 & 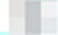 & 묘 & Annual P & -- & H & 回回 & 마맘 \\
\hline$\square$ & 1 & C & (C3) & $10: 00$ & arr 09:26 & $87 \mathrm{~min}$ & $E$ & -- & $=$ & (399) & sp wb & $1 / 1$ & = & $=$ & Return P & -- & D & Fin & 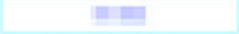 \\
\hline$\square$ & 1 & C & (A1) & $10: 00$ & arr 10:00 & $48 \mathrm{~min}$ & $E$ & -- & 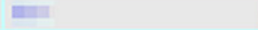 & (681) & sp wb & 0 & ㅁ & In & Acute $V_{i}$ & -- & $\mathrm{n} / \mathrm{m}$ & Ine & 물 \\
\hline$\square$ & 1 & C & (B4) & $10: 00$ & arr 10:00 & $59 \mathrm{~min}$ & $E$ & -- & in & (391) & sp wb & 0 & 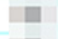 & $=$ & Return $\mathrm{P}$ & - & D & 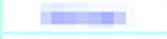 & +1 \\
\hline$\square$ & 1 & C & (D1) & $10: 20$ & arr 10:08 & $50 \mathrm{~min}$ & $E$ & -- & 맘 & $\cdots$ & sp wb & 4 & 回 & ] & Return P & -- & H & En & inin \\
\hline$\square$ & 1 & C & (A5) & $10: 20$ & arr 10:12 & $62 \mathrm{~min}$ & $E$ & -- & 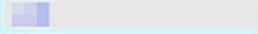 & $(405)$ & sp wb & 1 & $1=$ & 圆 & Return P & -- & D & ring & 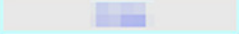 \\
\hline$\square$ & 1 & C & (A2) & $10: 20$ & arr 10:16 & $56 \mathrm{~min}$ & $E$ & -- & Ex & $(406)$ & sp wb & 3 & E & 표 & Acute $V_{i}$ & - & $n / m$ & Ex+1 & Di \\
\hline$\square$ & 1 & C & (B5) & $10: 20$ & arr 10:16 & $43 \mathrm{~min}$ & $E$ & -- & 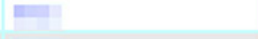 & (92) & sp wb & 0 & 回 & 맘 & Annual P & -- & $\mathrm{n} / \mathrm{m}$ & 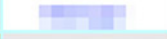 & 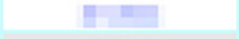 \\
\hline$\square$ & 1 & C & - & $10: 30$ & arr $10: 43$ & - & $E$ & -- & 라묘 & - & sp wb & $\cdots$ & E & $=$ & Nurse Vi & - & H & in & 를 \\
\hline$\square$ & 1 & C & $(\mathrm{C} 2)$ & $10: 40$ & arr 10:46 & $38 \mathrm{~min}$ & $E$ & -- & $=$ & (391) & sp wb & $1 / 1$ & H & $=$ & Return $\mathrm{P}$ & -- & H & in & ine \\
\hline$\square$ & 1 & C & (D2) & $10: 40$ & arr 10:45 & $37 \mathrm{~min}$ & $E$ & -- & 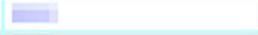 & (411) & sp wb & $1 / 1$ & E & $=$ & Return $\mathrm{P}$ & - & H & $=$ & inerien \\
\hline$\square$ & 1 & C & (A6) & $10: 40$ & arr 10:35 & $32 \mathrm{~min}$ & $E$ & - & \pm & $(408)$ & sp wb & 0 & E & 1 & Return $\mathrm{P}$ & -- & $\mathrm{n} / \mathrm{m}$ & ining & En \\
\hline$\square$ & 0 & C & - & $10: 40$ & CANCEL & - & $E$ & -- & $\square$ & $\cdots$ & sp wb & $\cdots$ & 四 & 플 & Acute $V_{i}$ & -- & D & 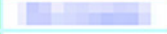 & Hivin \\
\hline$\square$ & 1 & C & (D1) & $11: 00$ & arr 11:00 & $63 \mathrm{~min}$ & $E$ & - & 回 & (111) & sp wb & 0 & = & 플 & Return $\mathrm{P}$ & - & D & Fin & \\
\hline$\square$ & 1 & C & (C1) & $11: 00$ & arr 10:27 & $72 \mathrm{~min}$ & $E$ & - & $=$ & $(406)$ & sp wb & 0 & $1=$ & = & Return P & - & $n / m$ & En & 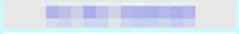 \\
\hline$\square$ & 1 & C & (A3) & $11: 00$ & arr 11:08 & $84 \mathrm{~min}$ & $E$ & -- & 10 & (149) & sp wb & 1 & E & a & Acute Vi & $-\cdot$ & $\mathrm{n} / \mathrm{m}$ & ining & and \\
\hline$\square$ & 1 & C & (A4) & $11: 00$ & arr 10:42 & $66 \mathrm{~min}$ & $E$ & -- & in & $(410)$ & sp wb & $7 / 1$ & 물 & 픔 & Annual $\mathrm{P}$ & - & H & in & 롤 \\
\hline$\square$ & 1 & C & -- & $11: 00$ & arr 11:42 & -- & $E$ & -- & 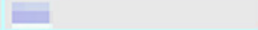 & -- & sp wb & $\cdots$ & ne & I & Nurse Vi & -- & D & inim & in \\
\hline ח & 1 & $r$ & (RA) & $11 \cdot n n$ & $\operatorname{arr} 10 \cdot 15$ & $72 \mathrm{~min}$ & $=$ & $\ldots$ & $E=$ & $(1148)$ & en wh & $n$ & 1 & IIII & Annualo 0 & $\ldots$ & $n$ & $=$ & $=$ \\
\hline
\end{tabular}

Fig. 3 OPWB Schedules View Layout for an Individual Clinic 
Table 1 External Services Employed by the Electronic Outpatient Whiteboard

\begin{tabular}{|c|c|c|}
\hline Service & Purpose & Information Received \\
\hline Patient Summary ${ }^{a}$ & $\begin{array}{l}\text { Retrieves summary of statistics for a } \\
\text { queried patient }\end{array}$ & $\begin{array}{l}\text { Known allergies, current medications, } \\
\text { illnesses }\end{array}$ \\
\hline Pager ${ }^{a}$ & Performs paging using specific inputs & None \\
\hline $\begin{array}{l}\text { Graduate Medical Education } \\
\text { (GME) Data }{ }^{\text {a }}\end{array}$ & $\begin{array}{l}\text { Retrieves specific information about trai- } \\
\text { nees }\end{array}$ & $\begin{array}{l}\text { Level of training, program description, } \\
\text { year }\end{array}$ \\
\hline $\begin{array}{l}\text { Enterprise Person Index (EPI) } \\
\text { Lookup }^{\text {a }}\end{array}$ & $\begin{array}{l}\text { Retrieves basic human resource informa- } \\
\text { tion on Vanderbilt employees }\end{array}$ & $\begin{array}{l}\text { Job code, name, email, username, de- } \\
\text { partment }\end{array}$ \\
\hline Patient EPI Lookup ${ }^{\text {a }}$ & $\begin{array}{l}\text { Retrieves basic demographic information } \\
\text { on a particular patient }\end{array}$ & Name, date of birth, address \\
\hline Provider Lookup ${ }^{\text {a }}$ & $\begin{array}{l}\text { Retrieves detailed information about a } \\
\text { provider }\end{array}$ & Specialty, department, provider id \\
\hline Appointment ${ }^{\mathrm{a}}$ & $\begin{array}{l}\text { Retrieves appointment information } \\
\text { about a particular patient visit }\end{array}$ & $\begin{array}{l}\text { Appointment schedule, insurance infor- } \\
\text { mation, provider, appointment du- } \\
\text { ration }\end{array}$ \\
\hline Census $^{a}$ & $\begin{array}{l}\text { Checks to see if a particular patient is } \\
\text { currently admitted in the hospital }\end{array}$ & $\begin{array}{l}\text { Returns a flag if a patient is admitted } \\
\text { elsewhere }\end{array}$ \\
\hline Core Data ${ }^{a}$ & Retrieves commonly used patient data & Vitals, basic labs, chemical balance \\
\hline $\begin{array}{l}\text { Vanderbilt Outpatient Order } \\
\text { Management (VOOM) API }{ }^{\text {a }}\end{array}$ & $\begin{array}{l}\text { Retrieves active outpatient orders for a } \\
\text { particular patient }\end{array}$ & $\begin{array}{l}\text { Order date, order time, person who re- } \\
\text { quested order }\end{array}$ \\
\hline $\begin{array}{l}\text { Vanderbilt Oncology Infor- } \\
\text { mation System (VOIS) API a }\end{array}$ & Retrieves chemotherapy orders & $\begin{array}{l}\text { Order date, order time, person who re- } \\
\text { quested order }\end{array}$ \\
\hline Immunization Forecaster ${ }^{b}$ & $\begin{array}{l}\text { Supports algorithm to calculate required } \\
\text { vaccines }\end{array}$ & Vaccines that are due \\
\hline
\end{tabular}

${ }^{\text {a }}$ Service from VUMC; ${ }^{\text {b }}$ Service from 3rd-party commercial vendor 


\section{References}

1. Brownstein JN, Hirsch GR, Rosenthal EL, Rush CH. Community Health Workers "101" for Primary Care Providers and Other Stakeholders in Health Care Systems: Journal of Ambulatory Care Management 2011; 34(3): 210-220.

2. Issom D-Z, Hagry C, Wodia Mendo L, Seng H, Ehrler F, Lovis C. Challenges and issues of geolocation in clinical environment. Stud Health Technol Inform 2012; 180: 447-451.

3. Doebbeling BN, Burton MM, Wiebke EA, Miller S, Baxter L, Miller D, Alvarez J, Pekny J. Optimizing perioperative decision making: improved information for clinical workflow planning. AMIA Annu Symp Proc 2012; 2012: 154-163.

4. Reddy MC, Dourish P, Pratt W. Coordinating Heterogeneous Work: Information and Representation in Medical Care. In: Prinz W, Jarke M, Rogers Y, Schmidt K, Wulf V, editors. ECSCW 2001 [Internet]. Dordrecht: Kluwer Academic Publishers; 2002 [cited 2015 Jun 23]. p. 239-58. Available from: http://link.springer.com/10.1007/0-306-48019-0_13

5. Pratt W, Reddy MC, McDonald DW, Tarczy-Hornoch P, Gennari JH. Incorporating ideas from computersupported cooperative work. Journal of Biomedical Informatics 2004; 37(2): 128-137.

6. Rasmussen R. Electronic whiteboards in emergency medicine: a systematic review. ACM Press; 2012 [cited 2015 Jun 16]. p. 483. Available from: http://dl.acm.org/citation.cfm?doid=2110363.2110418

7. Mainthia R, Lockney T, Zotov A, France DJ, Bennett M, St Jacques PJ, Furman W, Randa S, Feistritzer N, Eavey R, Leming-Lee S, Anders S. Novel use of electronic whiteboard in the operating room increases surgical team compliance with pre-incision safety practices. Surgery. 2012; 151(5): 660-666.

8. Bardram JE, Hansen TR, Soegaard M. AwareMedia: a shared interactive display supporting social, temporal, and spatial awareness in surgery. ACM Press; 2006 [cited 2015 Jun 16]. p. 109. Available from: http://portal.acm.org/citation.cfm?doid=1180875.1180892

9. Wong HJ, Caesar M, Bandali S, Agnew J, Abrams H. Electronic inpatient whiteboards: improving multidisciplinary communication and coordination of care. Int J Med Inform 2009; 78(4): 239-247.

10. Keep SL, Locker TE. The impact of a computerised whiteboard system on digit preference bias in the recording of emergency department process times. Eur J Emerg Med 2012; 19(3): 177-180.

11. Hertzum M, Simonsen J. Work-practice changes associated with an electronic emergency department whiteboard. Health Informatics J 2013; 19(1): 46-60.

12. Jensen J. United hospital increases capacity usage, efficiency with patient-flow management system. J Healthc Inf Manag 2004; 18(3): 26-31.

13. Unertl KM, Weinger MB, Johnson KB, Lorenzi NM. Describing and modeling workflow and information flow in chronic disease care. J Am Med Inform Assoc 2009; 16(6): 826-836.

14. Brindisi M, Bui R, Mazo J, Ong ZYM, Van Vleet S, Bailey R. Redesigning clinic workflows for electronic medical record integration. IEEE; 2013 [cited 2015 Jun 16]. p. 133-8. Available from: http://ieeexplore.iee.org/lpdocs/epic03/wrapper.htm?arnumber=6549507

15.MySQL: The world's most popular open source database [Internet]. MySQL: The world's most popular open source database. [cited 2015 Jun 23]. Available from: www.mysql.com

16. Health Level Seven International [Internet]. Health Level Seven International. 2015. Available from: www. hl7.org

17. Weinberg ST. Optimizing an Electronic Outpatient Whiteboard Through Analysis of Incoming HL7 Scheduling Messages. American Medical Informatics Association Annual Symposium; 2009 Nov; San Francisco, CA.

18. Aronsky D, Jones I, Lanaghan K, Slovis CM. Supporting Patient Care in the Emergency Department with a Computerized Whiteboard System. J Am Med Inform Assoc 2008; 15(2): 184-194.

19. Karsh, BT. Beyond usability: designing effective technology implementation systems to promote patient safety. Quality and Safety in Health Care. 2004; 13(5): 388-394.

20. Weinberg ST, Patterson BL. Embedding Real-Time Clinical Decision Support in An Electronic Whiteboard to Reduce Missed Opportunities for Influenza Vaccination. American Academy of Pediatrics' Council on Clinical Information Technology; 2010 Oct; San Francisco, CA.

21.PHP: Hypertext Preprocessor [Internet]. PHP: Hypertext Preprocessor. 2015. Available from: www.php. net 